\title{
Sports and the solitary kidney: What parents of a young child with a solitary kidney should know
}

\author{
Karen Psooy, MD, FRCSC \\ Division of Pediatric Urology, Winnipeg Children's Hospital, Winnipeg, MB
}

Cite as: Can Urol Assoc J 2014;8(7-8):233-5. http://dx.doi.org/10.5489/cuai.2306

Published online August 11, 2014.

Approved by the Canadian Urological Association May 22, 2014.

\section{Background and objectives}

The American Academy of Pediatrics (AAP) provides recommendations regarding sports in the child with a solitary kidney. ${ }^{1}$ They suggest that no restrictions be placed on noncontact sports, and that clinical judgement be used regarding placing any restrictions on contact/collision and limitedcontact sports.

This CUA guideline was initially developed in 2006 in accordance with the 2001 recommendations of the AAP, ${ }^{2}$ tailoring them to the young, sports-naïve child. As per the AAP recommendations, a literature search was carried out to determine what evidence is available on the risks of injury to the pediatric kidney through sports and whether these risks might be lowered. A detailed explanation of this literature search and conclusions are available. ${ }^{3}$ In 2013, this CUA guideline was updated, following a review of the updated 2008 AAP recommendations, ${ }^{1}$ and repeating the methods as described previously. New in this revision is guidance regarding the operation of motorized recreational vehicles.

\section{Guidelines}

In accordance with the AAP recommendations, the following information should be conveyed to the parent of a young child with a solitary kidney. Supporting documentation is provided following each statement with level of evidence based on the International Consultation on Urological Diseases (ICUD) system.

Parents of a young child with a solitary kidney should be informed of the following:

1. Their child has only one kidney. With current medical advancements, loss of that kidney would result in the need for dialysis or a renal transplant, and lifelong medications.

a. Evidence: Indisputable.

2. Renal injury, of any etiology, increases the risk/ degree of renal insufficiency.

a. Evidence - Level 3: Children with a normal solitary kidney in childhood have an increased risk of renal insufficiency as an adult., ${ }^{4,5}$

a. Evidence - Level 3: Trauma results in a decline of renal function on DMSA renal scan. ${ }^{6}$

3. While renal injury can result from contact/collision or limited contact sports, the risks are less than the risk of head injury.

a. Evidence - Level 3: In American football, which is considered a "collision" sport, kidney injuries occur significantly less often than head injuries. ${ }^{7}$

a. Evidence - Level 3: Those sporting activities most associated with high-grade renal trauma (bicycling, sledding, downhill skiing, snowboarding and equestrian), have more than a fivefold relative risk of head injury compared to renal injury. ${ }^{3}$

a. Evidence - Level 3: in 2011 there were no children awaiting renal transplantation as a result of renal trauma in the United States.

4. Parents should try to keep things in perspective. If they are not going to restrict a child from an activity based on the child having only one "head," then they should not restrict the child from that activity based on having only one kidney.

a. Evidence - Level 3: Those activities most associated with high-grade renal trauma (bicycling, sledding, downhill skiing, snowboarding and equestrian) have more than a fivefold relative risk of head injury compared to renal injury. ${ }^{3}$

5. Wearing protective padding during contact/collision and limited contact sports may decrease the risk of renal injury. 
a. Evidence - Level 4: Although protective padding is available, there is no evidence to demonstrate that they prevent renal injuries. ${ }^{8}$

6. The exact risk of renal injury from each sport is unknown; however, according to available studies, pedal bicycling, non-motorized sledding, downhill skiing/snowboarding and horse-related activities may carry a higher risk than other activities. $3,9,10$

a. Evidence - Level 3: Review of 9 published articles (2000-2005) reporting on pediatric renal trauma in North America shows that bicycling, sledding, downhill skiing, snowboarding and equestrian sports are implicated as the most common sportsrelated causes of high-grade renal trauma. ${ }^{3}$

- Bicycle riding may be made safer for the child by proper maintenance of the bicycle and handlebars.

1. Evidence - Level 3: Minor bicycle crashes can result in serious handle-bar associated injuries. ${ }^{11}$

2. Evidence - Level 4: As falling onto bicycle handlebars results in renal trauma, it is assumed, but not demonstrated, that proper maintenance of the bicycle and handlebars would help prevent renal injuries. ${ }^{11}$

- Sledding and horse-related activities should be done in a safe manner, ideally with supervision.

1. Evidence - Level 4: Most serious sledding injuries occur when sledding is done near or on roadways, when being towed by a motorized vehicle, or when a stationary object is hit. Therefore it is assumed, but not demonstrated, that renal injuries are less likely if sledding is limiting to noncrowded, designated hills, ideally with parental supervision. ${ }^{12,13}$

2. Evidence - Level 4: It is assumed, but not demonstrated, that horse-related injuries might be prevented if horses and activities are properly matched to the child's capabilities, if children avoid standing in positions where they might be kicked, and if there is parental supervision. ${ }^{14,15}$

- Downhill skiing may be safer than snowboarding. Injuries are more likely to occur in beginners. Formal instruction may be beneficial.

- Evidence - Level 3: When compared, renal injuries were significantly higher in snow-boarders than alpine skiers (all ages). ${ }^{16}$
- Evidence - Level 3: Injuries are more likely to occur in beginners (all ages). ${ }^{17}$

- Evidence - Level 3: While the overall risk of injury may not be decreased by formal instruction, the risk of potentially severe injuries may be lowered by taking lessons (all ages). ${ }^{17}$

7. Renal injuries from motor vehicle accidents (MVAs) are much more common than injuries from sports activities. Therefore, your child should always be in appropriate car restraints and be taught pedestrian and bicycle road safety.

a. Evidence - Level 3: Review of 7 published articles (2000-2005), reporting all grades of pediatric renal trauma in North America, shows that MVAs (including passenger and pedestrian) result in more renal trauma than sporting activities. ${ }^{3}$

8. The use of all-terrain vehicles (ATVs) by children is associated with high-grade kidney trauma. However, unlike other recreational activities mentioned in this guideline, there are formal recommendations against the operation of ATVs by all children less than 16 years of age, regardless of kidney number.

a. Evidence - Level 3: Renal injuries from 2-, 3and 4-wheeled recreational vehicles are associated with higher grade renal injuries than that caused by pedal bicycle injuries. ${ }^{9}$

a. Societies recommending against ATV operation in children:

- American Academy of Pediatrics 2000 (2-, 3 - and 4-wheeled recreational vehicles) ${ }^{18}$

- American Pediatric Surgical Association 2009 (ATVs) ${ }^{18}$

- Canadian Association of Pediatric Surgeons $2008\left(\mathrm{ATV}\right.$ s) ${ }^{18}$

- Canadian Pediatric Society $2012\left(\right.$ ATVs) ${ }^{19}$

Competing interests: Dr. Psooy declares no competing financial or personal interests.

\section{References}

1. Rice SG. Medical conditions affecting sports participation. Pediatrics 2008;121:841-8. http://dx.doi. org/10.1542/peds.2008-0080

2. Committee on Sports Medicine and Fitness. Medical conditions affecting sports and participation. Pediatrics 2001;107:1205-9. http://dx.doi.org/10.1542/peds.107.5.1205

3. Psooy K. Sports and the solitary kidney: How to counsel parents. Can J Urol 2006;13:3034-40.

4. Argueso LR, Ritchey ML, Boyle ET Jr, et al. Prognosis of patients with unilateral renal agenesis. Pediatr Nephrol 1992;6:412-6. http://dx.doi.org/10.1007/BF00873996

5. Argueso LR, Ritchie ML, Boyle ET Jr, et al. Prognosis of children with solitary kidney after unilateral nephrectomy. J Urol 1992;148:747-51.

6. Keller MS, Coln CE, Garza JJ, et al. Functional outcome of nonoperateively managed renal injuries in children. J Trauma 2004;57:108-10. http://dx.doi.org/10.1097/01.TA.0000133627.75366.CA

7. Grinsell MM, Butz K, Gurka MJ, et al. Sport-related kidney injury among high school athletes. Pediatrics 2012;130:e41-5. http://dx.doi.org/10.1542/peds.2011-2082 
8. Styn NR, Wan J. Urologic sports injuries in children. Curr Urol Rep 2010;11:114-21. http://dx.doi. org/10.1007/s1 1934-010-0098-4

9. Wu H-Y, Gaines BA. Dirt bike and all terrain vehicles: The real threat to kidneys. J Urol 2007;178:1672-4. http://dx.doi.org/10.1016/i.juro.2007.03.160

10. Sacco E, Marangi F, Pinto F, et al. Sports and genitourinary trauma. Urologia 2010;77:112-25.

11. Winston FK, Shaw KN, Kreshak AA, et al. Hidden spears: Handlebars as injury hazards to children. Pediatrics 1998;102:596-601. http://dx.doi.org/10.1542/peds.102.3.596

12. Shorter NA, Mooney DP, Harmon BJ. Childhood sledding injuries. Am J Emerg Med 1999;17:32-4. http:// dx.doi.org/10.1016/S0735-6757(99)90010-4

13. Noffsinger D, Nuss K, Haley K, et al. Pediatric sledding trauma: Avoiding the collision. J Trauma Nurs 2008;14:58-61. http://dx.doi.org/10.1097/01.JTN.0000327328.60405.f9

14. Jagodzinski T, DeMuri GP. Horse-related injuries in children: A review. WMJ 2005;104:50-4.

15. Eckert V, Lockemann U, Püschel K, et al. Equestrian injuries caused by horse kicks: First results of a prospective multicenter study. Clin I Sport Med 2011;21:353-5. http://dx.doi.org/10.1097/ JSM.0b013e318221840f
16. Wasden $C C$, Mclntosh SE, Keith DS, et al. An analysis of skiing and snowboarding injuries on Utah slopes. J Trauma 2009:67:1022-6. http://dx.doi.org/10.1097/TA.0b013e3181b0d559

17. Sulheim $S$, Holme I, Rodven A, et al. Risk factors for injuries in alpine skiing, telemark skiing and snowboarding - case control study. Br J Sports Med 2011;45:1303-9. http://dx.doi.org/10.1136/ bisports-2011-090407

18. Burd R. American Pediatric Surgical Association Trauma Committee position statement on the use of allterrain vehicles by children and youth. J Pediatr Surg 2009;44:1638-9. http://dx.doi.org/10.1016/i. ipedsurg.2009.03.026

19. Yanchar NL, Canadian Paediatric Society Injury Prevention Committee. Position statement: Preventing injuries from all-terrain vehicles. http://www.cps.ca/en/documents/position/preventing-injury-from-atvs. Accessed September 23, 2013.

Correspondence: Dr. Karen Psooy, Winnipeg Children's Hospital, AE301 - 840 Sherbrook St., Winnipeg, MB R3A 1S1; kpsooy@hsc.mb.ca 